\title{
視覚探索によるコンピュータ画面の色彩設計に関する検討
}

\author{
正会員 佐 々 和 博 (山武ビルシステム株式会社） 正会員 高 松 衛（富川大学） \\ 尃鬥会員 中嶋 芳 雄 (富山大学) 正会貝 中島 賛太郎 (富山大学)
}

\section{Study on Color Design for Computer Display by Visual Search}

Member Kazuhiro Sassa (Yamatake Building Systems Co., Ltd.),

Member Mamoru Takamatsu (Toyama University),

Fellow Member Yoshio Nakashima (Toyama University) and

Member Santaro Nakajima (Toyama University)

KEYWORDS : color design, computer display, visual search

\section{1. 緒言}

視覚探索は, 中枢での視鸴情報処理過程の研究や認知科学にお ける視知覚の心的メカ二ズムを検討する心理物理実験として以前 から広く実施されているい-31.

しかしこれを画面の見や导さの検討という，視喾工学的な目的 で実施した報然はみられない。

高画質化するコンピュータ・ディスプレイを有効・有益に活用 するには人間の視覚特性, 情報処理機能を考慮した㺺面設計が必 要である。これまでに筆者らは，高两質化しているビル管理用コ ンピュータシステムの設備監視用ユーーザ画面の色彩設計に関卞る 娭討を行ってきた

本研究ではコンピュータのューザ・インターフェイス画面にお

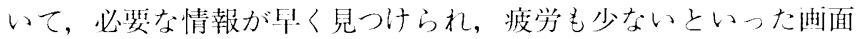
の見やすさを検討するため，ユーザ・インターフェイスの多色汇 面のモデルを作成し，その彩度を変えた視覚探索実験を行った。 その絬果, 画面全体の彩度が視営探索におよぼす影響が明らかに なった。これは，们面の色彩設計に対して彩度と見やすさの関係 の一端を示唆するものと考えられるので，本稿で報告する。

\section{2. 実験}

\section{1 多色画面のモデルと視覚探索課題}

コンピュータのューザ・インターフェイス画面はその心用装置 やシステムごとに多様であり, 絵, 网形, 文字列や記晃などで構 成される表示要菜 (以下オブジェクト) とその色彩も様々である。 またユーザの視環境も個々に違っている。本研究では再面を視角 $15 \circ 20^{\circ}$ 程度, 画面上のオブジェクトを視角 $1^{\circ} \sim 2^{\circ}$ 程度で見てい る場合を代表としてモデル化した。亦なわち $186 \times 247 \mathrm{~mm}$ の画面に $12 \times 12 \mathrm{~mm}$ の网形を 10 行 14 桁で計 140 倜配置し, 視距離を $50 \pm 15 \mathrm{~cm}$ と した。オブジェクトはホームベース型五角形および正方形とし， 視覚探素で検出すべき対象 (以下標的)を1個の正方形，残り 139 個を五角形の妨害刺激とした，五角形は上下左右に向きの変化を もたせて課題の難易度を上げ，探索時間が長くなるようにして，
観測される反忍時間の連動系成分の影響を小さくするようにし た. 図 1 に们面オブジェクトモデルを示す。

\section{2 方法}

2.2 .1 被験者

視力（矯正导含吉）の正常な28-50歳の成人 6 名（男性 3 名, 女性 3 名）を被験者とした。平均年齢は35.7歳であった。全員過 去の色党検查で異常は認められていない。们面は，パーソナルコ ンピュー夕 (Latitude CP M233ST, DELL)の液晶画面に呈 示し, 窒内照度は400 lx とした。

\section{2 .2 探索課題}

画面のオブジェクトモデルに対して, どの位置に標的の正方形 が现れるかをランダムとなるようにして，視覚探索のための画面 を36パタン作成した。この36パタンに対してオブジェクト（標的 と妨害刺激)の彩度を変えて, 高彩度采列 $(\mathrm{H})$, 中彩度系列 $(\mathrm{M})$, 無彩色系列 $(\mathrm{N})$ の各36探索課題を作成した。オブジェクトの色彩

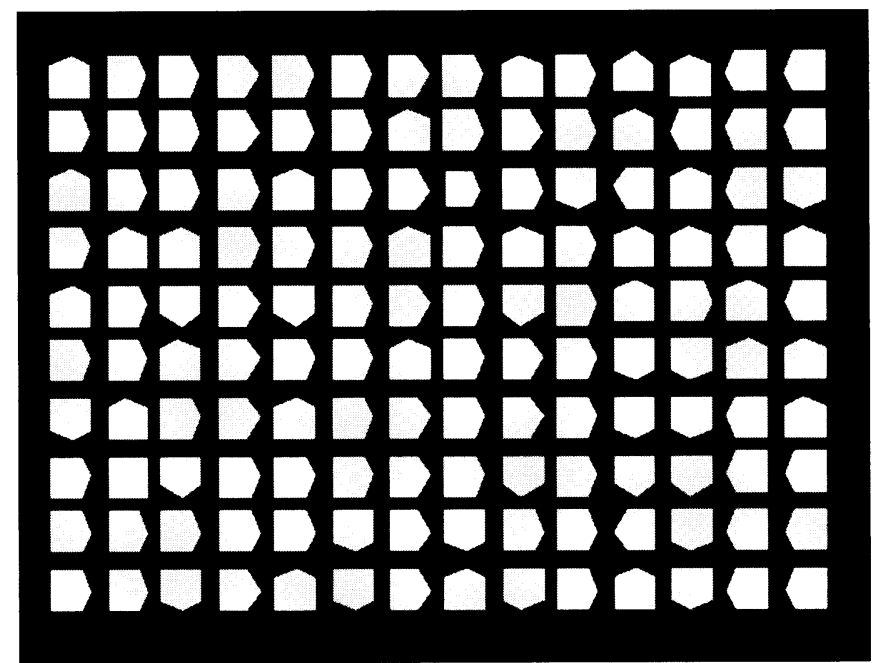

图 1 画面オブジェクトモデル

Fig. 1 An object model of display. 


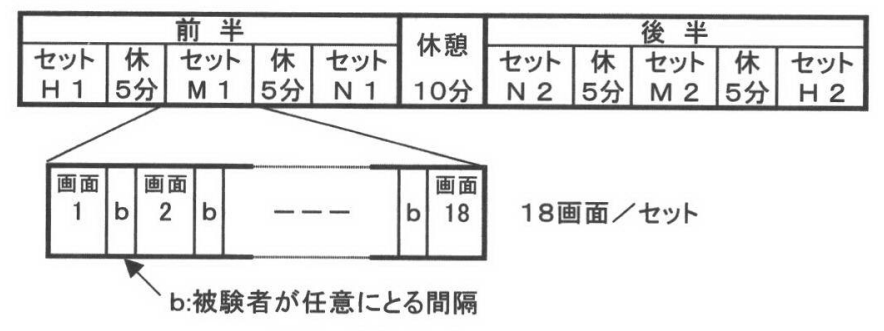

図 2 実験プロトコル

Fig. 2 Experimental protocol.

は R, G, B の 3 色と $\mathrm{R}+\mathrm{G}, \mathrm{G}+\mathrm{B}, \mathrm{B}+\mathrm{R}$ の計 6 色とした. 高彩 度系列では装置のパーソナルコンピュータで最高彩度とした。無 彩色系列を除き，各探索課題でオブジェクトの色彩 6 色が等確率 で出現するようにした。作成した探索課題のオブジェクトの平均 輝度は $\mathrm{H}, \mathrm{M}, \mathrm{N}$ 各彩度系列で $33.2 \mathrm{~cd} / \mathrm{m}^{2}, 17.6 \mathrm{~cd} / \mathrm{m}^{2}, 14.8 \mathrm{~cd} / \mathrm{m}^{2}$ であり，背景はすべて $0.48 \mathrm{~cd} / \mathrm{m}^{2}$ の黒である.

\section{2 .3 手順}

実験は $\mathrm{H}, \mathrm{M}, \mathrm{N}$ 各彩度系列の 36 課題を 2 つに分け，各彩度ご とに18画面を 1 実験単位（セット）とした。実験はこれらを前半 3 セット，休想をはさんで後半 3 セットの計 6 セット（H 1, M 1, N 1, N 2, M 2, H 2) で構成した. 明順応した状態で 課題の画面を呈示し，標的を探索できたときにボタンを押して応 答してもらった。なお，事前に実験内容の説明と視覚探索の練習 を数課題行った。視覚探索応答時間の 1 秒未満の端数は切り捨て て記録した．実験プロトコルを図 2 に示す。

\section{3. 実験結果}

視覚探索の結果を図 3 に示す．探索に要する時間は被験者によ り，また課題によって大きな違いが見られる。これを被験者別に 反応時間の範囲を 8 階級に分け，ヒストグラムにしたものが図 4 である。オブジェクトと背景の輝度の比は無彩色より高彩度の画
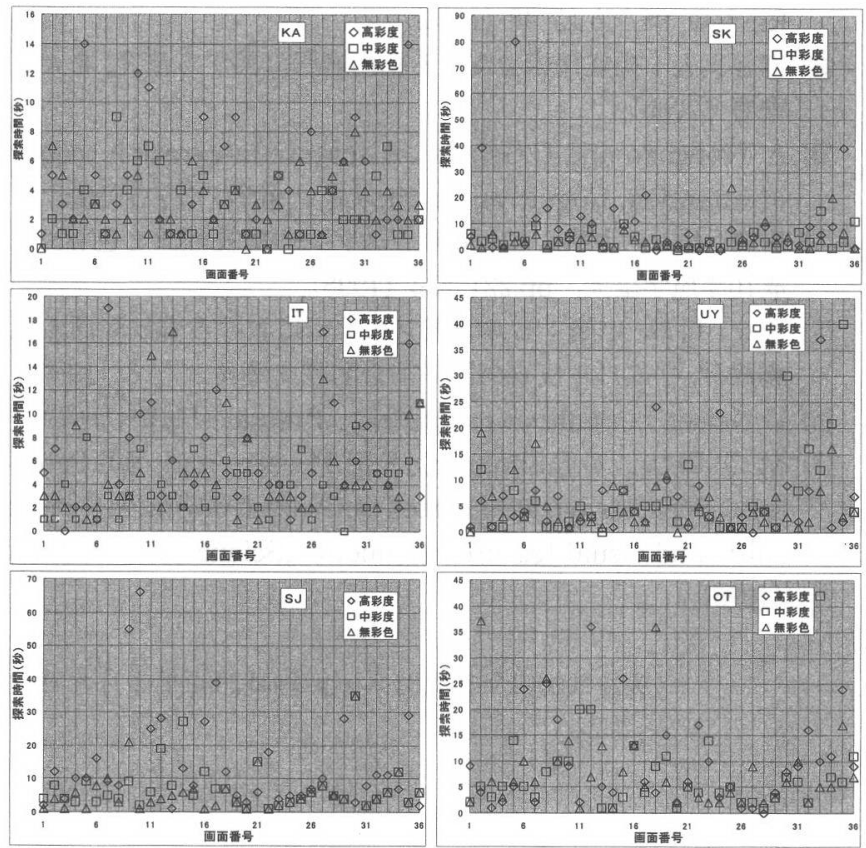

横軸は探索課題画面番号，縦軸は探索時間（秒) 図 3 視覚探索結果

Fig. 3 Results of visual search.
面の方が大きく，オブジェクトの形の識別は後者の方が容易であ ると考之られる。しかしどの被験者でも前者の方が探索に要する 時間が短くなっている. 前半 3 セット，後半 3 セットは，それぞ れ標的が現れる位置は同じであるが被験者はまったく気づかなか った。このことは同じパタンの反応時間が後続の試行で必ずしも 短くないことからも裏付けられ, 学習の影響はないと考えられる. すなわち学習を仮定すると, 反応時間は試行の順序に従って $\mathrm{H} 1>\mathrm{M} 1>\mathrm{N} 1$ および N $2>\mathrm{M} 2>\mathrm{H} 2$ と考えられるが，そ うした傾向は見られない.オブジェクトの彩度が違っていること が別の課題という印象をもたせること，また次々に呈示される目 前の課題に集中するため, 直前の探索結果が記憶される前に次の 課題に移行しているためと推定される.

なお，中間彩度では 6 名中 2 名（SK，OT）が無彩色と同等, 2 名 (IT, KA) が無彩色より短い階級に, 残り 2 名 (SJ, UY) が無彩色より長い階級に出現頻度の増加がみられた。

探索時間は個人差とともに, 被験者の実験時の緊張, 疲労, 覚
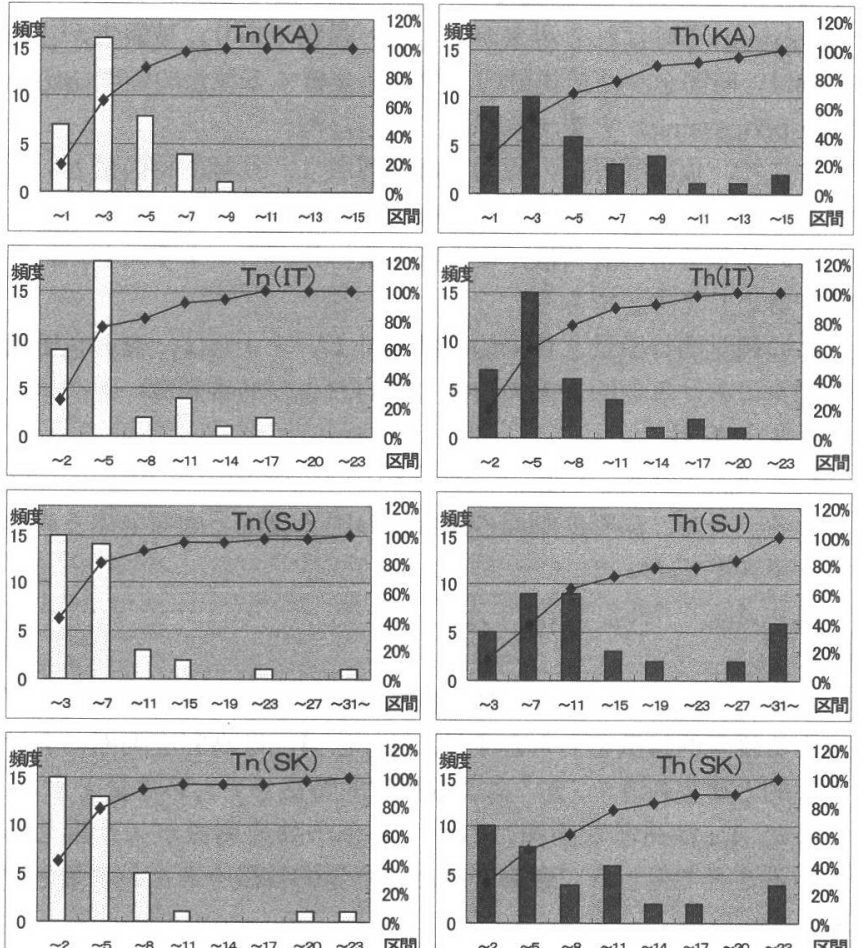

$\begin{array}{lllllllll}\sim 2 & \sim 5 & \sim 8 & \sim 11 & \sim 14 & \sim 17 & \sim 20 & \sim 23 & \text { 区間 }\end{array}$
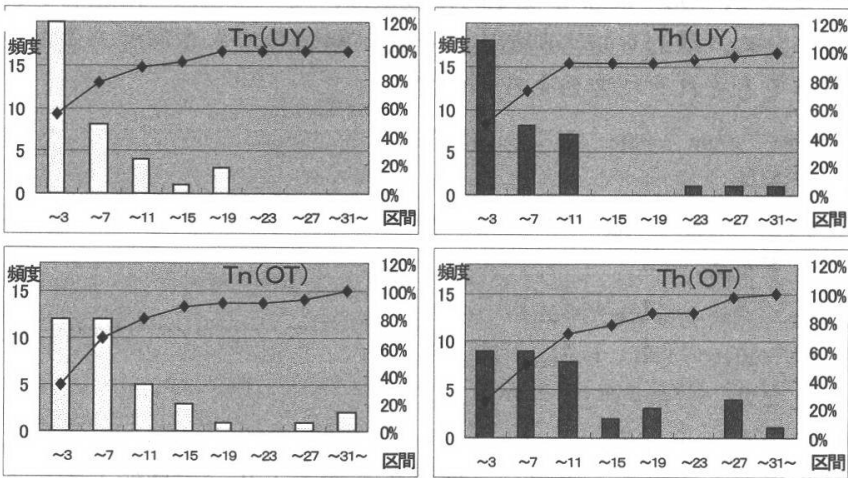

被験者 6 名の探索時間. 左の列は無彩色，右の列は高彩度の画面. 横軸は探索時間区間 (秒), 縦軸は頻度. 折線は累積百分率.

図 4 探索時間ヒストグラム

Fig. 4 Distribution of response time. 
醒レベルや気分など，心理的，生理的な諸条件が探索時間に影響 することが事前の実験で分かっている．しかしどの場合でも高彩 度より無彩色の画面での反応時間が短くなる特性は同じであっ た。

\section{4. 考察}

感覚のレベルでは刺激とその弁別に関して,

$\Delta R / R=K \quad$ (一定)

ただし， $R$ は刺激の值， $\Delta R$ は弁別間

というウエーバー（Weber）の法則が知られている.

本件の視覚探索実験は，単純に色彩と形という視覚刺激に対寸 る反応を感覚レベルでとらえたものではなく, 視覚情報処理機能 の処理時間をとらえるという，性質の異なるものである。しかし 大きな刺激を受けているときには，刺激の小さな差異の弁別が困 難になるという，刺激のコントラストに関わる現象としては類似 している.

今回の視覚探索は，個々の刺激を順々に探索してゆかなくても 標的が即座に目にとび込んでくるように見える，ポップアウト (pop-out) と呼ばれる現象が生じない課題であり, 被験者が注意 を向け，時間をかけて視野内の情報を分析古る注意的処理(attentive processing）を要する課題であった6).

ここで，仮に視野内の標的と妨害刺激に，視覚的特徵量といっ たものを想定し，妨害刺激を含む画面の中から，標的を探索する ための情報分析の負荷は，この特徵量の比（コントラスト）に関 係するとして考えてみる。

この視覚的特徴量を算術的に扱ってよいとすれば，無彩色画面 の探索に扔ける標的と画面全体（標的扔よび妨害刺激）とのコン トラスト $C_{\mathrm{n}}$ は,

$C_{\mathrm{n}}=A_{\mathrm{ftn}} /\left(A_{\mathrm{ftn}}+A_{\mathrm{fdn}}\right)$

となる。一方，高彩度画面の挆索における標的と画面全体とのコ ントラスト $C_{\mathrm{h}}$ は,

$C_{\mathrm{h}}=A_{\mathrm{ftc}} /\left(A_{\mathrm{ftc}}+A_{\mathrm{fdc}}+A_{\mathrm{cdc}}\right)$

となる。

ただし， $A_{\mathrm{ftn}}$ と $A_{\mathrm{fdn}}$ はそれぞれ無彩色の標的と妨害刺激の“形” による視覚的特徴をあらわす量， $A_{\mathrm{ftc}}$ と $A_{\mathrm{fdc}}$ は高彩度画面におけ る標的と妨害刺激の“形”による視覚的特徵をあらわす量とする.

また $A_{\text {cdc }}$ は高彩度画面において 6 色の妨害刺激が入り混じっ ていることで生じる“色彩”による視覚的特徴をあらわす量とす る.

ここで，“形”による視覚的特徵量は，その“色彩”に左右され ないため, 標的も妨害刺激も, それが無彩色でも高彩度の色彩で あってもそれぞれ変わらないので,

$A_{\mathrm{FT}}=A_{\mathrm{ftn}}=A_{\mathrm{ftc}}$

および

$A_{\mathrm{FD}}=A_{\mathrm{fdn}}=A_{\mathrm{fdc}}$

とすると,

$C_{\mathrm{n}}=A_{\mathrm{FT}} /\left(A_{\mathrm{FT}}+A_{\mathrm{FD}}\right)$

$C_{\mathrm{h}}=A_{\mathrm{FT}} /\left(A_{\mathrm{FT}}+A_{\mathrm{FD}}+A_{\mathrm{cdc}}\right)$

となり，分母の大きさから，

$C_{\mathrm{n}}>C_{\mathrm{h}}$ となる。

すなわち高彩度画面では，無彩色の画面と比べて標的と画面全 体の視覚的特徵量のコントラストが小さいため, 視覚情報の分析 負荷が大きくなり，標的の探索時間が長くなったものと考之られ る。
これは $A_{\mathrm{cdc}}$ の大きさに関係する現象であるため, 有彩色画面で あってもそれが単色であれば，

$$
A_{\text {cdc }}=0
$$

と考えられるので，無彩色の場合と同様であり，また逆に多色画 面で色の数が増え，その彩度が高くなるほど $A_{\mathrm{cdc}}$ が大きくなっ

て，標的の探索が長くなることが推察される.

この点については，今後の実験で確認してゆく予定である.

\section{5.まとめ}

視覚探索という心理物理実験課題老通じて，多色画面の彩度が 画面の見やすさにおよぼす影響の調查をを試みた。

探索時間は，視覚刺激に対与る中枢での情報処理量が反映され るといわれている7. 本件の画面モデルによる実験結果から，ユー ザが見るべき情報を画面に表示する場合に，全てのオブジェクト の彩度を高くすることはユーザの情報処理負荷を増加させる可能 性があることが示された。これはユーザ・インターフェイスとし て,“オブジェクトが多色で全体に色あざやかな画面は見にくくな る”という可能性を示唆している.

本研究が対象とする現実の多くのコンピュー夕応用装置やシス テムのユーザ・インターフェイス画面では，ただ見やすいだけで はなく，画面の内容や意味を分かりやすく表示することも重要で あり，そのためにオブジェクトに色を配してその色彩効果を生か す画面設計が必要である。

ユーザにとって見やすく分かりやすいコンピュータ画面とする ためには，各オブジェクトの重要性を考慮しながら，使用军る各 色の彩度が全体的に高くならないように，節度とめりはりのある 画面設計が重要であることが，告験的に確認できたものと考えら れる。

\section{参 考 文 献}

(1) A.Treisman and S.Gormican : Feature analysis in early vision, Evidence from search asymmetry, Psychological Review, 95, pp.15-48 (1988).

(2) 宮谷真人：視覚探索を支之る脳内過程に関する研究, 北大路 書房 (2000) .

(3) A.Treisman and G.Gelade: A feature-integration theory of attention, Cognitive Psychology, pp.97-136 (1980).

（4）川口，佐々，中嶋：ビル管理システムの監視画面と色彩, 平 成10年照学全大, pp.221-222（1998）。

（5）佐々，川口，中嶋：ビル管理システムにおける監視画面の色 彩設計, 平成11年度電気関係学会北陸支部連大, p.82(1999).

(6) U.Neiser : Cognitive psychology, Prentice-Hall (1967).

(7) M.Corbetta, G.L.Shulman, F.M.Miezen and S.E.Peter sen : Superior parietal cortex activation during attention shifts and visual feature conjunction,Science, 270-3, Nov. (1995).

（受付日2001年10月31日／採録日2002年 2 月 8 日） 